on the surfaces of the parts of the system and the diffusion in time of gases from the atmosphere through the glass envelope. Some recent studies of gettering phenomena and observations on the adsorption of gases on clean tungsten, tantalum and molybdenum surfaces conducted in the Bell Laboratories in connexion with vacua of $10^{-12}-10^{-14} \mathrm{~mm}$. are briefly referred to. Evaporated films, however, do not pump rare gases like helium and neon, and to remove thern use is made of the ion gauge, which, in addition to its use as a manometer, can also act as a pump. Its speed of pumping is much lower than that of a mereury diffusion pump or of evaporated films, but it has the particular advantages that there is no lower pressure-limit to its pumping action and that it can be incorporated in the tube being evacuated.

\section{COUNTING AND SIZING OF PARTICLES WITH THE FLYING- SPOT MICROSCOPE}

By D. CAUSLEY and Prof. J. Z. YOUNG, F.R.S. Department of Anatomy, University College, London M 1 Ecopic particles by the use of the flying-spot microscope have been tested with blood, nerve cells, dust particles and prepared standard sprays. The system involves scanning the preparation with twin spots of light, differently polarized, and passing the pulses generated by twin photocells to an anticoincidence circuit and then to a counting unit. The circuit ensures that a count is registered only on the sweep at which one of the spots crosses the particle; when both cross it the pulses are made to cancel each other ${ }^{1,2}$. Every time that a pulse passes to the eounter, the spot on the display tube is made more intense. This provides a visual display that shows which particles have been counted (Fig. 1).

Red cell counts. Red eell counts were carried out with the co-operation of Prof. M. Maizels. Twenty

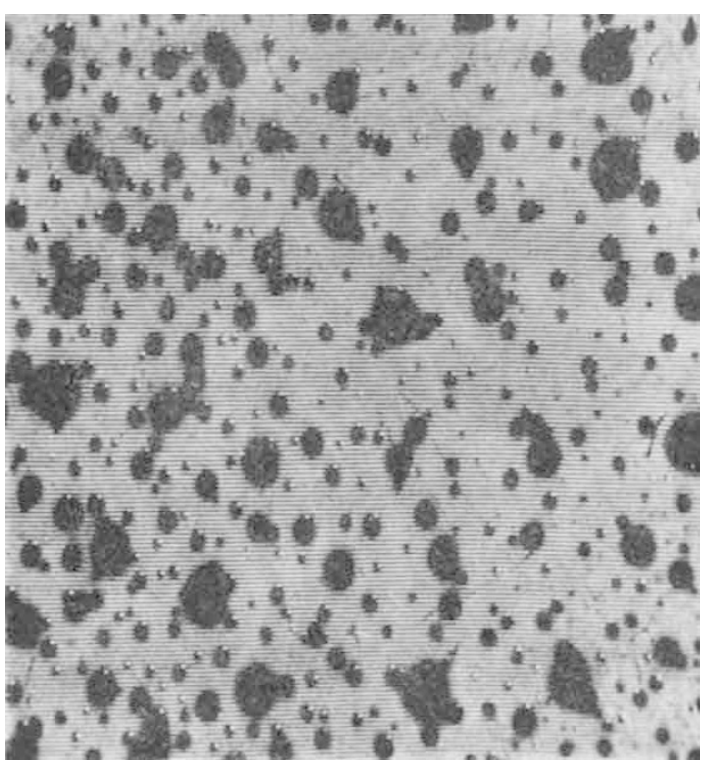

Fig. 1. View of test slide with machine presumed to be counting all particles. The bright spots indicate that a pulse has been passed to the counter
Table 1. HUMAN RED CORPUScle CoUnts (M/c. mm.) Columns 2 , 3 and 4 are visual counts, 5 and 6 machine counts. Counts 3 and 4 were made by a different observer to count 2 . The counts in columns 3 and 5 and 4 and 6 were from the same fllings of the slide.

\begin{tabular}{|c|c|c|c|c|c|}
\hline $\begin{array}{c}\text { (1) } \\
\text { Sample }\end{array}$ & $\begin{array}{c}\text { (2) } \\
\text { Visual } \\
\text { Hospital }\end{array}$ & $\begin{array}{c}\text { (3) } \\
\text { Visual } \\
\text { Lab. 1 }\end{array}$ & $\begin{array}{c}\text { (4) } \\
\text { Visual } \\
\text { Lab. 2 }\end{array}$ & $\begin{array}{c}\text { (5) } \\
\text { Machine } \\
1\end{array}$ & $\begin{array}{c}(6) \\
\text { Machine } \\
2\end{array}$ \\
\hline 1 & $3 \cdot 9$ & $3 \cdot 8$ & $3 \cdot 6$ & $3 \cdot 9$ & $3 \cdot 8$ \\
\hline 2 & $5 \cdot 1$ & $4 \cdot 4$ & $5 \cdot 3$ & $4 \cdot 5$ & $5 \cdot 3$ \\
3 & $4 \cdot 1$ & $4 \cdot 0$ & $3 \cdot 8$ & $3 \cdot 7$ & $4 \cdot 0$ \\
4 & $2 \cdot 5$ & $2 \cdot 4$ & $2 \cdot 6$ & $3 \cdot 0$ & $3 \cdot 0$ \\
5 & $1 \cdot 2$ & $1 \cdot 1$ & $1 \cdot 1$ & $1 \cdot 3$ & $1 \cdot 3$ \\
6 & $3 \cdot 2$ & $3 \cdot 1$ & $3 \cdot 2$ & $3 \cdot 0$ & $3 \cdot 3$ \\
7 & $3 \cdot 6$ & $3 \cdot 7$ & $3 \cdot 4$ & $3 \cdot 5$ & $3 \cdot 5$ \\
8 & $3 \cdot 5$ & $3 \cdot 8$ & $3 \cdot 4$ & $3 \cdot 5$ & $3 \cdot 6$ \\
9 & $3 \cdot 9$ & $3 \cdot 8$ & $3 \cdot 8$ & $3 \cdot 7$ & $3 \cdot 7$ \\
10 & $4 \cdot 5$ & $4 \cdot 5$ & $4 \cdot 5$ & $4 \cdot 8$ & $4 \cdot 6$ \\
11 & $4 \cdot 8$ & $4 \cdot 7$ & $4 \cdot 8$ & $4 \cdot 6$ & $4 \cdot 6$ \\
12 & $4 \cdot 7$ & $4 \cdot 4$ & $4 \cdot 3$ & $4 \cdot 4$ & $4 \cdot 4$ \\
13 & $4 \cdot 9$ & $4 \cdot 8$ & $4 \cdot 7$ & $4 \cdot 7$ & $4 \cdot 7$ \\
14 & $4 \cdot 6$ & $4 \cdot 7$ & $4 \cdot 5$ & $4 \cdot 7$ & $4 \cdot 7$ \\
15 & $3 \cdot 3$ & $3 \cdot 3$ & $3 \cdot 3$ & $3 \cdot 4$ & $3 \cdot 3$ \\
16 & $6 \cdot 7$ & $7 \cdot 0$ & $6 \cdot 8$ & $7 \cdot 1$ & $6 \cdot 2$ \\
17 & $4 \cdot 2$ & $4 \cdot 1$ & $4 \cdot 1$ & $4 \cdot 1$ & $4 \cdot 1$ \\
18 & $4 \cdot 5$ & $4 \cdot 3$ & $4 \cdot 2$ & $4 \cdot 2$ & $4 \cdot 2$ \\
19 & $4 \cdot 2$ & $4 \cdot 2$ & $4 \cdot 2$ & $4 \cdot 2$ & $4 \cdot 2$ \\
20 & $5 \cdot 2$ & $5 \cdot 2$ & $5 \cdot 2$ & $4 \cdot 9$ & $5 \cdot 0$ \\
\hline
\end{tabular}

samples of blood were counted by the routine visual method in the hospital laboratory. Two sub-samples were taken from each blood and counted both visually and by the machine in our Department. The visual counts were made with the standard method of recording corpuscles that lie upon the linos of a hæmocytometer. The machine counts were made on a microscopic field of known area, including about six hundred corpuscles. Each machine count was repeated three times on the same field, and the mean taken.

Table 1 and an analysis of variance show that although the bloods differed greatly, there were no consistent differences resulting from the methods of counting, whether by the hospital laboratory, a second visual observer or the machine.

The replication of the visual and machine counts enabled estimates of variance to be made; there were no significant differences, but the machine variance was possibly the smaller. The standard deviation is about $0.17 \mathrm{M} / \mathrm{c} . \mathrm{mm}$. by both methods, giving a coefficient of variation of about 4 per cent.

We may conclude that machine blood counts, though much quicker, are as accurate and consistent as visual ones-perhaps more so. The time involved in preparation of the specimen is equal in the two cases, but the counting takes 4 sec. with the machine, at least $4 \mathrm{~min}$. for the visual observer. The repetition of counts on a given field, which is so quickly undertaken by the machine, gives a further protection against error.

Table 2. Counts of THE NUMBer of Particles ReCORDed bY THE MACHINE AND THE TOTAL OF NUCLEI (AND NUCLEAR FRAGMENTS) MADE BY VISUAL OBSERVATION

Each count is for a strip $500 \mu$ wide extending from the pial surface to the white matter of the rat's cerebral cortex, stained with gallo-

$\begin{array}{cc}\begin{array}{c}\text { cyanin } \\ \text { Total particles } \\ \text { Machine count }\end{array} & \begin{array}{c}\text { Nuclei } \\ \text { Visual count }\end{array} \\ 1,336 & 1,253 \\ 1,183 & 1,220 \\ 1,172 & 1,303 \\ 1,164 & 1,181 \\ 1,410 & 1,424 \\ 1,044 & 1,389 \\ 1,197 & 1,170 \\ 1,296 & 1,357 \\ 1,464 & 1,503 \\ 1,389 & 1,357 \\ 1,289 & 1,242 \\ 1,018 & 1,048 \\ 1,315 & 1,258 \\ 1,240 & 1,104 \\ 1,349 & 1,087 \\ 1,372 & 1,069\end{array}$


Table 3. STFEL DUST PARTIOLES

\begin{tabular}{|c|c|c|c|c|c|c|c|}
\hline \multirow[t]{2}{*}{$\begin{array}{c}\text { (1) } \\
\text { Slide } \\
\text { No. }\end{array}$} & \multicolumn{4}{|c|}{$\begin{array}{l}\text { (2) } \\
\text { Total number of particles per } \\
\text { strip (all sizes) } \times 10^{3}\end{array}$} & \multicolumn{3}{|c|}{$\begin{array}{l}\text { (6) }(7) \quad(8) \\
\text { Total of particles } 0.5 \mu \text { - } \\
5 \mu \text { per strip } \times 10^{3}\end{array}$} \\
\hline & & ${ }_{2}$ & ${ }_{1}^{M}$ & 2 & $\underset{1}{\text { Visua }}$ & & ine \\
\hline$J_{3 / 1 / 1 B}$ & 497 & 525 & 490 & 510 & 38 & 107 & 119 \\
\hline & 513 & 475 & 522 & 496 & 30 & 200 & 186 \\
\hline$B B$ & 506 & 476 & 639 & 520 & 33 & 174 & 150 \\
\hline & 928 & 496 & 869 & 792 & 75 & 204 & 243 \\
\hline & 862 & 682 & 714 & 804 & 99 & 212 & 240 \\
\hline $7 B$ & 334 & 320 & 354 & 350 & 46 & 110 & 106 \\
\hline $8 A$ & 1,045 & 889 & 765 & 810 & 108 & 217 & 164 \\
\hline $10 A$ & 599 & 550 & 515 & 487 & 76 & 158 & 128 \\
\hline $13 \bar{B}$ & 349 & 385 & 362 & 405 & 47 & 152 & 181 \\
\hline $19 \mathrm{~A}$ & 516 & 473 & 494 & 484 & 60 & 170 & 120 \\
\hline $21 \boldsymbol{A}$ & 818 & 784 & 898 & 860 & 68 & 210 & 248 \\
\hline 254 & 640 & 675 & 590 & 620 & 77 & 214 & 158 \\
\hline $33 B$ & 309 & 315 & 374 & 348 & 44 & 104 & 88 \\
\hline $34 B$ & 639 & 475 & 560 & 496 & 80 & 171 & 192 \\
\hline $37 A$ & 416 & 386 & 540 & 492 & 44 & 118 & 141 \\
\hline $38 A$ & 067 & 435 & 395 & 463 & 96 & 196 & 157 \\
\hline $39 B$ & 316 & 343 & 373 & 393 & 68 & 124 & 139 \\
\hline $40 B$ & 615 & 555 & 402 & 569 & 107 & 215 & 140 \\
\hline $42 A$ & 951 & 510 & 365 & 400 & 119 & 132 & 156 \\
\hline $43 B$ & 461 & 420 & 432 & 392 & 45 & 118 & 182 \\
\hline
\end{tabular}

Counts of nerve cells in sections. The value of the method for counting norve cells was tested with sections of the cerebral cortex of the rat stained with gallocyanin to show nuclei and Nissl substance. Counts were made with the machine of all the particles in a series of strips between the pial surface and the white rnatter, followed by a visual count of all the nuclei and parts of nuclei in the same strips. The figures show a general agreement, and the mean difference does not differ significantly from zero.

Dust particle counts. Counting of dust particles may be particularly difficult if there are many near and below the limit of resolution. The maintenance of a constant criterion for counting of imperfectly resolved objects is difficult for both human or machine counting, but is likely to be more variable for the former. Machine counts of such dust were usually considerably higher than those of human observers.

Table 3 shows the results with a series of thermal precipitation samples of steel dust particles. Columns 2 and 3 show visual counts made by observers in

Table 4. Counting and Siging of Circutar partioles on a Thest Field $800 \mu \times 500 \mu, 16 \mathrm{~mm}$. objective, $10 \times$ eyeplece. Top, visual counts by three different observers. Centre, counts of different parts of the sample by the machine. Bottom, comparison of means

\begin{tabular}{|c|c|c|c|}
\hline Vfsual & 1 & 2 & 3 \\
\hline Total & 415 & 430 & 407 \\
\hline $\begin{array}{c}\text { Up to } 5 \mu \\
5-10 \\
10-15 \\
15-20 \\
20-25 \\
25-30 \\
>30\end{array}$ & $\begin{array}{r}183 \\
145 \\
48 \\
20 \\
10 \\
7 \\
2\end{array}$ & $\begin{array}{r}202 \\
133 \\
45 \\
30 \\
10 \\
8 \\
2\end{array}$ & $\begin{array}{r}182 \\
133 \\
44 \\
27 \\
11 \\
8 \\
2\end{array}$ \\
\hline Machtne & 1 & 2 & 3 \\
\hline Total & 408 & 396 & 416 \\
\hline $\begin{array}{l}\text { Up to } 5 \mu \\
5-10 \\
10-15 \\
15-20 \\
20-25 \\
25-30 \\
>30\end{array}$ & $\begin{array}{r}189 \\
136 \\
41 \\
21 \\
12 \\
7 \\
2\end{array}$ & $\begin{array}{r}180 \\
121 \\
50 \\
24 \\
11 \\
8 \\
2\end{array}$ & $\begin{array}{r}192 \\
150 \\
44 \\
15 \\
15 \\
8 \\
2\end{array}$ \\
\hline Total & \multicolumn{2}{|c|}{$\begin{array}{c}\text { Mean of } 3 \text { counts } \\
\text { Visual } \\
418\end{array}$} & $\begin{array}{c}\text { Machine } \\
408\end{array}$ \\
\hline $\begin{array}{r}0-5 \mu \\
5-10 \\
10-15 \\
15-20 \\
20-25 \\
25-30 \\
>30\end{array}$ & & & $\begin{array}{r}184 \\
136 \\
45 \\
20 \\
18 \\
8 \\
2\end{array}$ \\
\hline
\end{tabular}

Table 5. Strips of Rat CokthX showing how the Proportion of ARTICLES ATTRIBUTABLE TO GLIAL AND OTHBR NUCLRT CAN BE restimated by Cotnting Large Partiches SEParately

\begin{tabular}{|c|c|c|c|}
\hline $\begin{array}{c}\text { All nuclei } \\
\text { Visual connt }\end{array}$ & $\begin{array}{c}\text { All particles } \\
\text { Machine count }\end{array}$ & $\begin{array}{c}\text { Neurons } \\
\text { Visual count }\end{array}$ & $\begin{array}{c}\text { Particles more } \\
\text { than 7 5 } \\
\text { Machine count }\end{array}$ \\
\hline 1,197 & 1,252 & 727 & 725 \\
1,296 & 1,291 & 760 & 689 \\
1,457 & 1,372 & 790 & 787 \\
1,056 & 1,098 & 840 & 630 \\
\hline
\end{tabular}

Sheffield and London without consultation on standards. There are considerable differences between the counts by visual methods and between these and the machine counts; but the mean differences over colurans 2-5 are not significantly different from zero. The replicated machine counts for columns 4 and 5 agree better with each other than do the visual counts of the two observers. Column 6 shows a visual count of the particles of less than $5 \mu$ in this material, and 7 and 8 are replicated machine counts of this valuc. The last two agree well with each other but are higher than the visual counts. Presumably the machine is taking a different criterion of what is to constitute a particle at the limit of resolution.

Sizing. Estimates of size are made with this system by comparing the pulses generated with pulsos of known duration in such a way that successively smaller and smaller particles are rejected from the count ${ }^{1,3}$. In this way the particles in the test-slide shown in Fig. 1 were measured into $5 \mu$-size groups. Table 4 shows comparison of these measurements with those made visually on a photograph at $300 \times$ by three observers. The agreement is remarkably good.

The same method has been used for estimating the number of neurons, as distinct from all particles, in strips of cerebral cortex of the rat, by counting separately the particles greater than and less than $7 \cdot 5 \mu$.

Table 5 shows that there is moderately good agreement between the estimates obtained in this way and the counts of neurons made visually on the same strips.

Conclusions. 'These results show that the method is capable of providing reliable counts and measuremonts of a variety of particles. Difficulties have been met in balancing the gain factor in the amplification channels from the two photocells when the contrast of the specimen is poor. Other difficulties arise if the particles overlap or touch, and with objects of shapes involving long re-entrants. For some purposes, estimates of the errors due to such factors can be made. The special usefulness of the machine is its speed of operation, making it possible to take more numerous counts than would be practicable by direct vision. For routine counts of easy material, such as blood, it provides substantial economies. For difficult material such as dust, containing particles at the limit of resolution, it may well be that the machine provides approximations that are more consistent than those of a human observer.

Our thanks are due to the Nuffield Foundation for its support, and to Prof. M. Maizels and Mr. F. Fellingham of University College Hospital and Messrs. Maturana, Michie, Sholl, Stanier and Taylor for their help with counting and otherwise, and to Cinema-Television, Ltd., for assistunce with equipment.

[May 28

${ }^{2}$ Roberts, F., and Young, J. Z., Proc. Inst. Elec. Eng., 99, 747 (1952). ${ }^{2}$ Causley, D., Roberts, F., and Young, J. Z., Electronics, 26, 137 (1953). -Taylor, W. K., Brit. J. App. Phys. (Supp. No. 3), S173 (1954). 